\title{
HERMENÉUTICA JURISPRUDENCIAL. DE LA HIPOTROFIA DE LOS DERECHOS SUBJETIVOS A LA GESTIÓN DEL TRÁNSITO DE UNA SOCIEDAD HOMOGÉNEA A OTRA HÍBRIDA
}

\author{
JURISPRUDENTIAL HERMENEUTICS. FROM THE \\ HYPOTROPHY OF SUBJECTIVE RIGHTS TO THE \\ MANAGEMENT OF THE TRANSITION FROM A \\ HOMOGENEOUS SOCIETY TO A HYBRID ONE
}

\author{
RAÚl C. CANCIO FERNÁNDEZ \\ Tribunal Supremo de España
}

Recibido: 13/06/2019 Aceptado: 18/09/2019

\section{RESUMEN}

Nuestros jueces no son meros proclamadores de las reglas jurídicas y, consecuentemente, el proceso de interpretación y aplicación de las normas no se ventila merced a un silogismo simple. La referencia a valores y el cada vez más rápido cambio de las circunstancias sociales, culturales y económicas han acentuado el dinamismo del sistema jurídico, liquidez que se ha visto reflejada en leyes perfunctorias, de escasa calidad técnica, que difícilmente pueden abarcar los distintos supuestos conflictivos y que deben ser aplicadas en un contexto marcado por una creciente e irreversible diversidad socio-cultural. Consecuentemente, en esta coyuntura, el rol del juez se potencia extraordinariamente, lo que no significa asignar al juez de funciones propias de los restantes poderes, por más que se esté convirtiendo en el complemento indispensable de la ley, sometido, eso sí, a un intenso deber de motivar sus decisiones con sujeción a los estrictos cánones de la argumentación jurídica. La motivación se convierte así en un auténtico ensayo de persuasión, del que pende la valoración de la legitimidad última de las formas de ejercicio de la función jurisdiccional. La única 
respuesta para lograr una percepción sociológica favorable de la función hermenéutica encomendada a las altas instancias jurisdiccionales radica, por tanto, en la expectativa cultural de que los jueces deben comportarse independientemente. Estamos por tanto ante lo que se podría denominar un ejercicio de «legitimidad social hermenéutica», es decir, el grado de confianza y de credibilidad social que una institución (el sistema de Justicia en este caso) amerita entre la ciudadanía.

Palabras clave: Hermenéutica jurisprudencial. Doctrina. Sistema judicial. Jueces. Aplicación de la norma. Legitimidad por ejercicio.

\section{ABSTRACT}

Our judges are not mere proclaimers of legal rules and, consequently, the process of interpretation and application of rules is not ventilated thanks to a simple syllogism. The reference to values and the increasingly rapid change in social, cultural and economic circumstances have accentuated the dynamism of the legal system, liquidity that has been reflected in perfunctory laws, of poor technical quality, that can hardly cover the different conflicting assumptions and that must be applied in a context marked by a growing and irreversible sociocultural diversity. Consequently, at this juncture, the role of the judge is strengthened extraordinarily, which does not mean assigning the judge functions proper to the other powers, even though it is becoming the indispensable complement to the law, subject, of course, to an intense duty to motivate their decisions subject to the strict canons of legal argumentation. Motivation thus becomes a veritable trial of persuasion, from which hangs the assessment of the ultimate legitimacy of the forms of exercise of the jurisdictional function. The only answer to achieve a favorable sociological perception of the hermeneutic function entrusted to the high jurisdictional instances lies, therefore, in the cultural expectation that judges should behave independently. We are therefore before what could be denominated an exercise of "hermeneutic social legitimacy", that is to say, the degree of confidence and social credibility that an institution (the Justice system in this case) deserves among the citizens.

Keywords: Jurisprudential hermeneutics. Doctrine. Judicial system. Judges. Application of the norm. Legitimacy by exercise. 
Se impone advertirles, estimados lectores, antes de cualquier otra consideración que, si el Profesor Gómez García ha tenido la cortesía de invitarme a participar en este proteico número monográfico del Anuario de la Facultad de Derecho de la Universidad de Extremadura, no ha sido, ni mucho menos, por mi pericia en el ámbito de la hermenéutica jurídica académica, sino por algo tan prosaico como pertenecer, desde hace casi veinte años, al Gabinete Técnico del Tribunal Supremo, sin duda, el operador jurídico que simboliza de manera arquetípica a la interpretación como la actividad fundamental del Derecho. Y, en particular, de su Sala de lo Contencioso-Administrativo la cual, tras la reforma operada por la LO 7/2015, se ha erigido como paradigma de un sistema o régimen casacional en el que el criterio discrecional exige una labor exegética singularmente desarrollada.

Hecha esta necesaria advertencia en cuanto al criterio empleado para mi cooptación y que seguro facilitará la comprensión de las siguientes páginas, resulta incontrovertible que nuestros jueces no son meros proclamadores de las reglas jurídicas y que este proceso de interpretación y aplicación de las normas no se ventila merced a un silogismo simple. El modelo de organización política nacido de la Revolución Francesa situó la garantía de la seguridad jurídica en el principio de legalidad; la Ley, como expresión de la voluntad general, no encontraba otros límites que el respeto a los derechos inviolables del ciudadano, cristalizados en la libertad y la propiedad. Desde esa premisa, el juez era independiente por quedar sometido exclusivamente al imperio de la ley. La referencia a valores y el cada vez más rápido cambio de las circunstancias sociales, culturales y económicas han impulsado y acentuado el dinamismo del sistema jurídico, liquidez que se ha visto reflejada en leyes perfunctorias, de escasa calidad técnica, que difícilmente pueden abarcar los distintos supuestos conflictivos y que deben ser aplicadas en un contexto marcado por una creciente e irreversible diversidad cultural. 
Consecuentemente, en esta coyuntura, el rol del juez se potencia extraordinariamente, hasta el punto de que algunos han visto en la proliferación de cláusulas generales, tan característica de nuestra época, una forma de delegación en el juez el poder de decisión. Pero lo cierto es que no cabe asignar al juez funciones propias de los restantes poderes, por más que se esté convirtiendo en el complemento indispensable de la ley, sometido, eso sí, a un intenso deber de motivar sus decisiones con sujeción a los estrictos cánones de la argumentación jurídica. La motivación se convierte así en un auténtico ensayo de persuasión, del que pende la valoración de la legitimidad última de las formas de ejercicio de la función jurisdiccional.

En este sentido, la tarea encomendada al mal llamado Poder judicial por nuestra Constitución de 1978 no es, en definitiva, otra cosa que la expresión del principio democrático en el que se sostiene aquella. No en vano, el sintagma «garante de derechos» sobre el que se construye la función del juez, aparece umbilicalmente unido a la observancia del procedimiento, que es tanto como decir a la corrección de la labor diaria del juzgador, cuya legitimidad tiene precisamente su anclaje en el respeto a las formas que exige el Derecho y, consecuentemente, a la propia Carta Magna.

La opción elegida por el constituyente, en el que el sistema de control de la constitucionalidad de las leyes se radicó en un órgano singular y no en una Sala de Justicia enmarcada en un órgano jurisdiccional ordinario, dota a nuestro Tribunal Constitucional de un valor añadido circundante respecto del Poder judicial y forja, también, un sistema jurisprudencial dual y, de modo aferente, un ineludible diálogo institucional configurado a partir de la jurisprudencia emanada del Tribunal Supremo y la doctrina constitucional producida por quien es su más cualificado hermeneuta. 
Decía Juan Antonio Xiol, privilegiado testigo del funcionamiento de ambas instituciones, que «(L)a relación entre ambos tribunales no puede fundarse en principios autoritativos que deben considerarse en gran parte ajenos al funcionamiento del sistema jurídico, manteniendo la falacia de considerar el principio de jerarquía como el que informa la actuación de los órganos jurisdiccionales superiores.».

En efecto, esa relación, por el contrario, debe sustentarse sobre la base de una ponderación activa derivada de la conversación institucional entre el Tribunal Supremo y el Tribunal Constitucional, construida sobre el respeto que debe guardar el viejo caserón de las Salesas de las decisiones y los criterios sentados por la sede de Domenico Scarlatti en la interpretación de la Constitución y la determinación del alcance de los derechos fundamentales y, recíprocamente, en el reconocimiento por parte de éste de la jurisprudencia del Supremo como expresión del contexto vivencial del Derecho.

Por cierto, abro aquí un brevísimo paréntesis al hilo del citado concepto de jurisprudencia, dada su medular relación con este tipo de hermenéutica. De las escasas certezas que nos iban quedando con el transcurso de los años, la que dispensaba el artículo 1.6 del Código Civil parecía sólida: la jurisprudencia era aquella doctrina que, de modo reiterado, establece el Tribunal Supremo al interpretar y aplicar la ley, la costumbre y los principios generales del derecho. Amén.

Sin embargo, la reforma operada por la citada LO 7/2015 en el ámbito de la jurisdicción contencioso-administrativa, ha venido a resquebrajar el mito de la objetivización que, mediante la abstracción, se opera a partir de varias sentencias reiteradas. Cuando la Sala Tercera del Tribunal Supremo considera que un recurso presenta interés casacional objetivo (ICO), ese concepto jurídico indeterminado no implica en modo alguno que también su objeto lo sea. Más al contrario, el muy definido efecto de apreciar su concurrencia en un recurso, es la formación de jurisprudencia. 
Repárese por tanto que el ICO no es el fin del nuevo régimen casacional, sino el medio, el instrumento que va a facilitar que una pretensión cristalice jurisprudencialmente por su benéfica repercusión sobre la comunidad jurídica. En otras palabras, la tarea de uniformar la aplicación judicial del derecho se deposita ahora en la formación de la jurisprudencia. Pues bien, más de tres años después de la entrada en vigor de la referida reforma, aun no se sabe con certeza cuando hay o no jurisprudencia, extremo que, como ya se comprenderá, resulta nuclear en el nuevo rito de admisión del recurso de casación contencioso.

Antes de la reforma, y merced al referido artículo 1.6 del Código Civil, resultaba axiomático que únicamente tras una segunda sentencia del Tribunal Supremo en sentido idéntico, podía considerarse creada jurisprudencia sobre la cuestión. Hoy resulta discutible que esa previsión sea aplicable en el marco de la nueva casación contenciosa.

$\mathrm{Y}$ es que resulta poderosamente contraintuitivo que en un sistema casacional en el que se prioriza la salvaguarda de la unidad del ordenamiento jurídico a través de la formación de Jurisprudencia, en detrimento de la protección y reparación de los derechos subjetivos de los litigantes, pueda sostenerse la necesidad de que una doctrina sea reiterada al menos dos veces para alcanzar el estado de jurisprudencia. Y ello, fundamentalmente, porque no es en absoluto previsible que vaya a pronunciarse una segunda sentencia en el mismo sentido sobre esa cuestión. Nótese que una de las presunciones de existencia de interés casacional objetivo más frecuentemente argüidas por los recurrentes es que en la resolución impugnada se haya aplicado normas en las que se sustente la razón de decidir sobre las que no exista jurisprudencia ¿̇y cuando existe? Si se invocan sentencias dictadas antes de la entrada en vigor de la reforma, no hay duda ¿̇pero sí únicamente se trae a colación una sentencia dictada al socaire de la nueva regulación casacional? ¿Acaso la Sala Tercera va a dictar una nueva sentencia sobre esa cuestión, cuando ya se ha pronunciado y fijado la doctrina legal correspondiente? 
Por el contrario, los que defienden la tesis de que nada ha cambiado en el sistema de fuentes diseñado por el legislador de 1974 a pesar de las singularidades que ha traído esta reforma casacional, apuntan a la confusión subyacente entre el ICO y la jurisprudencia. Según esta postura, una sola sentencia de la Sala Tercera sería, en efecto, más que suficiente para descartar la existencia de ICO de un recurso ulterior sobre la misma cuestión. Ahora bien, el decaimiento del referido interés no es lo mismo que la creación de jurisprudencia. Y así, la doctrina legal solo nacería con, al menos una segunda sentencia que, añaden, su búsqueda debería ser auspiciada y promovida por todos los operadores jurídicos implicados, desde la instancia hasta el propio Tribunal Supremo, en una constante pesquisa por alicatar posibles taras en sus razonamientos jurídicos, otorgando a la jurisprudencia una naturaleza insoslayablemente evolutiva en consonancia con la paralela liquidez de la actual sociedad.

En este sentido, y aun concediendo dialécticamente que el artículo 1.6 CC diseña un concreto concepto de jurisprudencia en el que la virtualidad de la sentencia única es claramente ectópica, lo cierto es que de facto no puede sostenerse una diferencia sustancial entre lo que pueda ser conceptuado como «jurisprudencia» en el sentido que se le ha dado y lo que pueda ser una sola sentencia dictada en este nuevo modelo casacional. Y es que del hecho de que sobre una sola sentencia no pueda fundarse un recurso de casación no puede inferirse que aquella carezca completamente de efecto vinculante sobre los «terceros» operadores jurídicos y por ello erga omnes o, lo que es igual, un efecto que trasciende al de las partes y al propio Tribunal que la dictó, situado más allá de las previsiones jurídico-formales del Código Civil. Potencialidad que, en palabras del magistrado Ramón Trillo (STS de 8 de junio de 1991 [casación 3794/1991] se expresa por el valor como doctrina de su propia jurisprudencia, que el ciudadano tiene derecho a esperar que normalmente sea seguida y respetada como un adherente complementario del ordenamiento jurídico. 
Hace casi setenta años y con una presciencia asombrosa, el profesor Puig Brutau [La Jurisprudencia como fuente del Derecho (Interpretación creadora y arbitrio judicial)] decía que el «(v)alor persuasivo de las sentencias es independiente de que concurran los requisitos que el Tribunal Supremo exige para que su doctrina pueda ser alegada como fundamento de un recurso de casación», añadiendo que «cuando es necesario prever la firmeza de un Tribunal de instancia, será preciso tener en cuenta el criterio del Tribunal Supremo, con independencia de que se trate de doctrina reiterada, pues ha de presumirse que el criterio afirmado en una sola ocasión es el punto de partida de una doctrina y no una declaración que ha de quedar desvirtuada cuando de nuevo se resuelva el mismo problema. No se trata de que una sola sentencia de nuestro Tribunal Supremo deba tener eficacia vinculante para los Tribunales inferiores; basta con que su valor sea persuasivo y que su criterio confiera solución eficaz a un problema social para que sea necesario tenerla en cuenta al intentar profetizar cuál será la resolución que corresponda en un conflicto de intereses según el derecho vigente».

Ignoro si resulta o no preciso acomodar al vigente contexto ritual un artículo 1.6 CC redactado hace cuarenta y cinco años. Sobre lo que no albergo dudas es que con independencia de que jurídico-formalmente pueda o no construirse un recurso de casación sobre una sola sentencia del Tribunal Supremo, su Sala Tercera debe ser la primera en ponderar adecuadamente la capacidad persuasiva de cada una de sus resoluciones, en su mismidad, en una exégesis pro activa no sólo en favor del justiciable, sino también, desde luego, en un ejercicio de autoprotección del nuevo e inaplazable régimen casacional que, de otra manera, sufriría un absurdo por innecesario desgaste por rozamiento interno.

\section{III}

Cerrado este excursus acerca de la nueva conceptualización del término, debe insistirse en la imperativa la necesidad de que el trabajo del 
Tribunal Supremo y del Constitucional no sólo sea complementario y respetuoso, sino que su labor nomofiláctica se retroalimente con la producción doctrinal de cada uno de ellos, enriqueciendo de esta manera el ordenamiento jurídico español, al aherrojar la protección de los derechos del justiciable de forma integral y completa. Esta saludable e imprescindible interacción, se ha manifestado, procesalmente, desde hace años y particularmente en el terreno de la admisibilidad de los recursos y el empleo del instrumento de la discrecionalidad como criterio racionalizador del acceso a la jurisdicción.

Una resolución tardía no hace justicia a las partes litigatoris especialmente a la perjudicada por la dilación, frecuentemente buscada por el otro contendiente para diferir la firmeza de la sentencia; pero tampoco resulta operativo el sistema basado únicamente en el ius constitutionis, pues si se mantiene el atropellado ritmo legislador de los últimos años, el Tribunal Supremo acaba haciendo, con sus resoluciones, necropsia del Derecho, en lugar de resolver en plazo razonable las cuestiones que se suscitan en los órganos inferiores, dispensándoles el criterio más adecuado y, en la medida de lo posible, analizando derecho vigente.

Como es de todos sabido, desde el 22 de julio de 2016, la Sala $3^{\mathrm{a}}$ se halla enfrascada en lograr que el nuevo régimen casacional instaurado por la disposición final $3^{\mathrm{a}}$ de la Ley Orgánica 7/2015, salga con bien del envite. Se trata, como es patente, de una verdadera mutación en nuestro sistema de justicia administrativa e incluso, más en general, en nuestro propio ordenamiento jurídico. La reforma se inspira en dos criterios fundamentales: de una parte, y a diferencia de lo que venía ocurriendo en el pasado, el nuevo recurso de casación contencioso-administrativo amplía extraordinariamente su objeto, siendo susceptibles de impugnación, en principio, todas las sentencias las Salas de lo Contencioso-Administrativo -incluso las dictadas en apelación- siendo irrelevante la cuantía del asunto o la materia tratada, así como las dictadas por los Juzgados de lo ContenciosoAdministrativo en única instancia, si bien en este caso es necesario que contengan una doctrina gravemente dañosa para el interés general y sean 
susceptibles de extensión de efectos. En otras palabras, cualquier problema jurídico importante puede ahora tener acceso a la casación.

Por otro lado, como contrapeso a la extraordinaria ampliación de su objeto, el nuevo recurso de casación contencioso-administrativo es restrictivo y exigente en cuanto a los requisitos de admisión, configurándose como clave de bóveda del sistema la necesidad de que la impugnación presente un «interés casacional objetivo para la formación de jurisprudencia», una suerte de la «especial trascendencia constitucional», tributaria a su vez de la grundsätzliche verfassungsrechtliche Bedeu-tung alemana de 1993, pues en ambos conceptos jurídicos indeterminados subyace la idea de que no basta el interés subjetivo que naturalmente tiene el recurrente, sino que es preciso que el problema jurídico planteado tenga un interés objetivo para el conjunto de la comunidad jurídica, pugnando por facilitar que la labor nomofiláctica y unificadora de la jurisprudencia pueda operar en todos los sectores necesitados de ella.

En el nuevo recurso de casación contencioso-administrativo prima el ius constitutionis sobre el ius litigatoris, pero como defendía Giuseppe Chiovenda, sin abandonar el esfuerzo en cohonestar la defensa del individuo con el interés general. Así, un reciente Auto de 1 de junio de 2017 recuerda que «(p)or más que se haya enfatizado la relevancia del llamado "ius constitutionis" en la articulación jurídica del nuevo recurso de casación, en ningún caso puede caracterizarse como un cauce para plantear cuestiones interpretativas del Ordenamiento en abstracto y, por ende, desligadas de las circunstancias concurrentes en el caso litigioso concernido».

Como ha advertido muy atinadamente el presidente de la Sala $3^{\mathrm{a}}$, Luis M. Díez-Picazo, el criterio del «interés casacional objetivo» ha supuesto un severo cambio de mentalidad de los magistrados, pero no sólo de ellos, sino de todos los operadores jurídicos concernidos por la reforma, desde los abogados a los servicios jurídicos autonómicos y locales, pasando por letrados de la administración de justicia, abogados del 
Estado o funcionarios judiciales. Probablemente lo más importante a este respecto es que la práctica de la Sala $3^{\text {a }}$ vaya demostrando su solvencia para discernir cabalmente qué temas tienen un auténtico interés más allá del puramente subjetivo de la parte recurrente, de manera que el Tribunal pueda ocuparse únicamente de lo que en cada momento sea objetivamente importante -la abogada y lobista norteamericana Lisa Paddock tenía muy claro que «(L)a verdadera razón para que una petición de certiorari progrese no radica en aspectos jurídico procesales. La clave está en presentar tu caso en el entorno adecuado; y para ello es imprescindible que en tu esquina haya alguien que conozca cómo hacer que los Justices «quieran» oír tu caso»- lo que redundará, ineluctablemente, en que el nuevo recurso de casación adquiera la necesaria legitimación en la comunidad jurídica.

Ya lo dijo el juez del Tribunal Supremo Federal de los Estados Unidos, Felix Frankfurter: «(S)in un estudio adecuado, no puede haber una reflexión adecuada; sin una reflexión adecuada, no puede haber una discusión adecuada; sin una discusión adecuada, no puede producirse ese completo y fructífero intercambio intelectual indispensable para adoptar por el Tribunal decisiones que sean sabias y persuasivas. A menos que el Tribunal priorice sus propios criterios para otorgar la revisión de los casos, inevitablemente se enfrentará con la acumulación de retrasos o dispondrá de su asunto esencial de una forma demasiado veloz y por lo tanto demasiado superficial.»

En este diseño es claro que el trámite de admisión adquiere una importancia crucial, pues la valoración de si un recurso presenta interés casacional objetivo, lejos de ser una operación mecánica, implica ahora un notable margen de apreciación, convirtiéndose en una actividad exigida ab initio, en el mismo pórtico de entrada casacional, pues esa evaluación de la concurrencia de interés casacional objetivo, supone un verdadero y auténtico juicio de prosperabilidad de la pretensión casacional. 
IV

Ahora bien, esta hipertrofia discrecional advertible en ambas instituciones, ha generado un fenómeno insoslayable y de enorme trascendencia jurídico-social.

Partamos de una premisa incontrovertible: los regímenes procesales preexistentes tanto en el Tribunal Constitucional -antes de la Ley Orgánica 6/2007, de 24 de mayo- como en la Sala de los Contencioso-Administrativo del Tribunal Supremo -antes de la Ley Orgánica 7/2015, de 21 de julio- avocaban a ambas instituciones al colapso irreversible.

En la mejor tradición malthusiana, el legislador optó, merced a los citados instrumentos de la «especial trascendencia constitucional» y el «interés casacional objetivo», por trasladar las tesis contenidas en el Ensayo sobre el principio de la población tal como afecta al futuro progreso de la sociedad al ámbito de la admisión. De la misma forma que el clérigo anglicano consideraba que el exponencial crecimiento demográfico era un suicidio social al resultar absolutamente incompatible con los recursos existentes, el insoportable incremento del número de recursos de amparo y casación registrados anunciaba una crisis irresoluble en ambos órganos. De tal forma que si para Malthus, las guerras, las epidemias y los desastres naturales debían contemplarse como una forma natural de regular el desmán reproductivo, el reforzamiento del ius constitutionis era la única vía de racionalizar el funcionamiento de ambos tribunales, a costa, inevitablemente, de hipotrofiar la tutela judicial de los justiciables.

Este ejercicio de radical objetivación tanto del recurso de amparo como del recurso de casación -acompañado de una indisimulable voluntad disuasoria- se ha traducido en un escenario de incertidumbre e inseguridad para los operadores jurídicos que acuden a una y otra sede. En los nuevos escenarios rituales el interés propio del recurrente es un mero vehículo para alcanzar la relevancia constitucional o el interés objetivo, de manera que por muy apreciable que pueda ser el litigio de la parte o muy aberrante la injusticia procesal subyacente, la admisión solo 
procederá si el actor acredita la concurrencia de esos sintagmas facilitadores, y todo ello, además, a mayor gloria de valores como la «seguridad jurídica», la «igualdad», e iincluso! la «protección de los derechos de los ciudadanos», principios que alumbraron estas reformas procesales.

Esta falta de equilibrio entre el perfectamente comprensible «¿qué hay de lo mío?» del recurrente que acude a la vía casacional o de amparo y la salvaguarda de la unidad del ordenamiento jurídico a través de la formación de Jurisprudencia o de la interpretación uniforme de la Constitución, acarrea un riesgo adicional pues, si un tribunal inferior no teme que un tribunal superior pueda revocar o anular sus decisiones, no se sentirá impelido de cumplir la doctrina sentada por ese órgano superior. De esta manera, la idea de que hay que delegar en la jurisdicción ordinaria la aplicación de la doctrina constitucional resulta quimérica. De igual forma, si los órganos de la jurisdicción ordinaria empiezan a advertir que el Tribunal Supremo únicamente dicta sentencias en casos que supongan alguna innovación jurisprudencial, el grado de concernimiento por su doctrina decaerá.

Las reformas operadas por las referidas LO 6/2007 y 7/2015, teleológicamente diseñadas para un fin tan prosaico como fue el alivio de sus registros, han venido a subvertir, de facto, la función tuteladora que constitucionalmente aún corresponde a los recursos de amparo y de casación, sacrificando los derechos individuales de gran parte de los ciudadanos que acuden a ellos en el ara de un difuso interés de la comunidad jurídica. Y, nótese, con el beneplácito de Estrasburgo, que en Arribas Antón c. España primero, y más recientemente en Fraile Iturralde v. España, ha convalidado estas reformas sostenidas en la discrecionalidad, la objetivación y la magra fundamentación de sus decisiones.

Admitamos que, al día de hoy, el Tribunal Constitucional es el más cualificado intérprete de la Constitución, pero también que, en la mayoría de los casos, no actúa ya como órgano de garantías al haber sido delegadas, casi en exclusiva, en la Jurisdicción ordinaria. Pero 
paradójicamente, y en paralelo, el Tribunal Supremo ha minimizado su rol como verdadero órgano de justicia, vindicando la formación de jurisprudencia como monocultivo en detrimento de su papel jurisdiccional icomo si una y otra tarea no fuesen perfectamente compatibles! No se olvide que nunca podrá existir jurisprudencia si no hay antes un pleito con nombres, apellidos y pretensiones.

Del principio que establecía que las leyes y las demás normas jurídicas valen en la medida que respetan los contenidos esenciales de los derechos fundamentales, se está transitando a que éstos derechos cuentan en la medida que los reconocen las leyes, retornando así a la cultura jurídica inspirada en normas o deberes jurídicos por encima de los derechos, con el riesgo de rehacer el camino desde el Estado Constitucional de Derecho al Estado Legal de Derecho, donde la Ley se convierte en el centro de todo el sistema normativo, deconstitucionalizándose de esta manera los ordenamientos jurídicos.

En el penúltimo blockbuster de Marvel [iojo spoilers!] el neomalthusiano Thanos, con un chasquido de dedos soluciona el previsible colapso del universo: elimina a la mitad de los seres vivos en modo random. Los chasquidos legislativos de 2007 y 2015 están aliviando ciertamente las estadísticas del Constitucional y del Supremo, ipero a qué precio!

\section{V}

Si la hermenéutica procesal, como acabamos de advertir, resulta esencial para comprender cabalmente la cuestión del derecho de acceso a los tribunales y la protección que la jurisdicción dispensa a resultas del ejercicio de las acciones, no lo es menos en la gestión del debate en torno a la globalización y su relación con la modernidad y la posmodernidad, el particularismo y el universalismo, fruto del tránsito de una sociedad homogénea y uniforme a una sociedad pluralista y diversa, como, recordarán, advertíamos tímidamente $a b$ initio. 
$\mathrm{Y}$ es que resulta una obviedad, por incontrovertible, que el incremento exponencial de los flujos migratorios ha transformado en los últimos veinte años el panorama socio-cultural español, quebrándose el modelo anterior de cohesión y convivencia social, e imponiéndose la necesidad de arbitrar un nuevo patrón de coexistencia y gestión de la diferencia. Del modo como se manejen las diferencias de las minorías con la cultura hegemónica, respetando el derecho de los individuos a mantener sus referentes simbólicos y sus singularidades grupales en el marco de una democracia homologable, dependerá el éxito o el fracaso de nuestra convivencia en el siglo XXI.

Trasladando esta fenomenología al ámbito de las relaciones jurídicas, esta pluralidad se manifiesta en la existencia de diferentes concepciones culturales del derecho y de la justicia. El pluralismo jurídico, aun siendo una noción central de la antropología del derecho, resulta en ocasiones inaprehensible. Y ello porque su definición se encuentra estrechamente ligada a las representaciones del Estado y del derecho que el propio exégeta tenga, además de que la implicación de disciplinas como la sociología, la antropología y la historia diversifican los enfoques.

La solución de un eventual conflicto entre diversidad versus universalidad, o si se prefiere, la fijación de los límites de esa porosidad jurídica, tiene que pasar forzosamente por el cedazo irrenunciable de la dignidad de la persona. Por ello, debe reconocérsele el derecho a la protección de su identidad cultural o, dicho de otro modo, a la protección de la cultura del grupo social al que pertenece. Esto no supone en modo alguno que de la existencia de diversos grupos culturales y de la pertenencia efectiva del sujeto a ellos se deduzca que hay un deber de respeto a todas las culturas y en todo caso. Sólo nacería esa obligación de respeto en la medida en que el ser humano se realizare en ellas.

La praxis tradicional para resolver estos conflictos ha sido tradicionalmente esgrimir la cláusula de «orden público», pero no siempre se advierte el carácter convencional, dinámico, en una palabra, cambiante 
de esta noción, que no puede ser presentada a la manera de un límite objetivo, definido e impertérrito. Si ante estos conflictos característicos del pluralismo jurídico la respuesta es la negación de la posibilidad misma de la diversidad, nos encontraremos con efectos perversos e indeseados, en el sentido de que con frecuencia lo que se producirá será un enjuiciamiento de la legitimidad de una cultura para justificar prácticas que parecen incompatibles con el mínimo exigido por la integración de la diferencia ante un caso en el que, en realidad, lo que se ventila es el conflicto entre dos culturas, dos sistemas de valores y de vida, y a esos efectos la visión «puramente» técnico-jurídica es a todas luces insuficiente para solventar el problema.

Si el hecho de la multiculturalidad es irreversible, el grado de tensión y conflictividad que este factor genera en la sociedad depende de la actitud de los sujetos en conflicto y de la evolución de sus relaciones, en un proceso de tipo acción-reacción. Las comunidades minoritarias pueden tomar el camino de la secesión cultural, cerrándose al exterior y reaccionando agresivamente frente a la cultura dominante; una actitud, calificada por G.Sartori [La sociedad multiétnica (2001)] como «tribalización cultural», supone un evidente peligro para la paz social. Desde el otro factor de la ecuación, los poderes públicos, instados por una mayoría social intransigente frente a valores ajenos al entorno cultural, puede tener la tentación de imponer unos supuestos principios de la civilización occidental -inducidos de la tradición cristiana y los postulados de la secularización- como condición a la concesión de la plena ciudadanía a los inmigrantes y la consiguiente integración social, llevando a cabo una doble política de uniformidad cultural combinada con el retorno a sus países de origen de los no integrados. No cabe duda que el efecto inmediato de una actitud del Estado como la descrita incrementará la tensión social, favoreciendo la proliferación de guetos culturales hostiles y refractarios frente a la sociedad dominante.

Por todo ello es aconsejable, en consecuencia, que el tratamiento de los conflictos derivados de la heterogeneidad cultural se produzca en la 
vía legislativa en lugar de la judicial, reubicando la discusión a una sede donde es posible examinar con mayor detalle y a la vez con más alcance (y con más legitimidad) el contraste entre los diferentes modelos culturales, la justificación de sus pretensiones normativas y, en su caso, el rechazo de aquellas que resulten inasumibles.

En cualquier caso, las respuestas exigen conciliar, en un equilibrio complicado, sin duda, la comprensión y valoración de la diversidad, con la posibilidad -más aún, el deber- de evaluar las pretensiones normativas de las diferentes culturas. Resulta necesario distinguir con fineza entre pretensiones que resultan razonablemente dignas de la protección y garantía que comporta su traducción, su reconocimiento como derechos, y las que no se hacen acreedoras a ese instrumento, ya sea porque no lo necesitan, bien porque pueden ser satisfechas por otras vías más adecuadas o, finalmente, porque no lo merecen. El aserto «mi cultura me obligó a hacerlo» no puede erigirse como argumento o coartada jurídica para quien abusa de los demás ni, por supuesto, la mejor manera de proteger el principio de igualdad de oportunidades.

En efecto, la cohonestación de la paridad de oportunidades en el seno de las sociedades multiculturales se erige como el verdadero debate de fondo en este ámbito. La igualdad de oportunidades nació con la intención de evitar los privilegios sociales vinculados al origen, de manera que el destino social de los individuos no viniera predeterminado desde el nacimiento.

Por tanto, la pregunta clave de nuestros días es si la lucha por el reconocimiento de la diferencia corre paralela o, por el contrario, nos aleja de la tradicional lucha por la igualdad social. Mientras que la versión esencialista del multiculturalismo insiste en que no es posible concebir la justicia y, por tanto, las relaciones sociales de igualdad, sin respetar las diferencias culturales, autores como BARRY, B. [Culture and Equality: An Egalitarian Critique of Multiculturalism (2001)] sostienen que la defensa del multiculturalismo es incompatible con el igualitarismo social. 
Si entendemos que una oportunidad indica un estado de cosas objetivo (no interpretable según la cultura, la ideología o la religión), si creemos que el valor de una oportunidad es independiente de las disposiciones culturales para aprovecharla, entonces no tiene sentido singularizar oportunidades a los diferentes grupos culturales. Si, por el contrario, se considera que una oportunidad es un concepto que depende de un contexto y no existe una disposición correctora, no puede decirse en puridad que exista la oportunidad, sino únicamente una mera potencialidad pasiva. Sin la ley que permite a los partidarios del sikhismo conducir sin casco, sin la libertad de usar el pañuelo islámico en los colegios públicos, sin los menús vegetarianos en los comedores de empresa o sin la opción de sustituir el domingo por el viernes o el sábado como día de descanso, no se puede afirmar que haya igualdad de oportunidades para determinados grupos religiosos o culturales. Formulado en negativo ¿es razonable que una persona, debido a su cultura o a sus creencias, esté obligada a pagar unos costes morales muy elevados para poder aprovechar una oportunidad?

Como es fácil advertir, la respuesta estriba en la responsabilidad individual que se está dispuesto a atribuir a las creencias culturales o religiosas. Si consideramos, como hacen los exégetas más liberales, que las creencias culturales y religiosas son el fruto de una elección libre, entonces las personas que las asumen son responsables de tales creencias y no pueden argüir que su cultura o su religión les impide aprovechar las oportunidades físicas y pretender, al mismo tiempo, que ése sea un factor ajeno a su responsabilidad, una singularidad que la sociedad debería compensar de algún modo de cara a igualar sus oportunidades con el resto de la población.

En cambio, si consideramos, como hacen las tesis comunitaristas, que dichas creencias no entran dentro del ámbito volitivo de la persona, sino que vienen impuestas por el entorno y forman parte esencial de la persona como el color de los ojos o el de la piel, parangonables por tanto a las incapacidades físicas, entonces la sociedad no debería cargar sobre 
esos individuos la asunción de esas creencias, como tampoco es admisible responsabilizar a nadie por ser un tullido.

Pero incluso, si se aceptara que los derechos culturales y religiosos merecen, si se da el caso, una compensación especial no porque las creencias no sean elegidas - como piensan los liberales-, sino porque implican prácticas sociales cuya realización es más difícil de llevar a cabo porque son minoritarias (porque se enfrentan a más obstáculos sociales, materiales e institucionales que las creencias mayoritaria), todavía habría que resolver un problema añadido: los costes especiales pueden ser tan elevados que acaben generando un problema de cohesión social, perjudicando la prestación de los servicios públicos. Sin embargo, nótese que al fin y al cabo ésta es una objeción más política que moral. No se afirma que sea moralmente malo compensar los diferentes costes económicos de la realización efectiva de la libertad religiosa, sino que es políticamente imprudente hacerlo, por más que la cohesión social sea un ingrediente político básico de la vida moral de la sociedad.

La segunda parte del problema sí es apriorísticamente moral. Sufragar los costes especiales derivados de las minorías culturales y religiosas puede reducir las prestaciones sociales y económicas que reciben los demás. Por ejemplo, la negativa de los testigos de Jehová a recibir transfusiones de sangre y, en consecuencia, su deseo de utilizar un tratamiento alternativo que podría ser mucho más caro, tanto que la atención sanitaria a la que todos tenemos derecho se reduciría. Nos enfrentamos aquí a un problema ético de prioridad de los recursos sanitarios limitados, de justicia distributiva de la sanidad. El racionamiento es un problema común a los sistemas sanitarios actuales, pero la cuestión que ahora se abre es si los derechos culturales y religiosos deben contar como una necesidad más a tener en cuenta en la distribución justa de los recursos limitados, una necesidad moralmente equiparable al resto de necesidades sanitarias de los enfermos. Pero fíjense, la razón de tal desigualdad no obedece en puridad a una falta de respeto hacia los derechos culturales y religiosos, sino que se trata de una consecuencia directa de la laicidad de 
las instituciones públicas, por una parte, y de la eficiencia social, por otra. Por muy injusto que parezca que no se investigue tanto en alternativas a las transfusiones de sangre como en otro tipo de tratamientos médicos, es lo mismo que sucede con cualquiera de las enfermedades minoritarias que existen, que el número reducido de sus afectados actúa como un claro desincentivo para una costosa investigación. De haber una injusticia, ésta no se fundamenta en la discriminación cultural o religiosa, de modo que no ha lugar para una discriminación positiva por razones culturales o religiosas.

El modo de escapar de tan incómoda encrucijada es eludiendo la distinción entre libertad y circunstancias. La igualdad de oportunidades no debe consistir únicamente en compensar por las circunstancias ajenas a los individuos mientras se permite el resultado desigual de sus elecciones libres, sino en dirimir los resultados sociales que producen explotación y dominación de aquéllos que simplemente producen modos diferentes de vivir. Los primeros son moralmente injustificados, mientras que los segundos son éticamente legítimos. Si la creencia cultural de un individuo le coloca en situación de explotación o dominación ante otro sujeto o ante algún grupo cultural, entonces deja de tener igualdad de oportunidades para llevar a cabo el modo de vida que puede llegar a elegir. Pero si vivir conforme a sus creencias no provoca explotación ni dominación -ni a él ni a los demás-, los resultados desiguales que su modo de vida pueda producir son un efecto inequívocamente legítimo.

Y ese sí, indiscutiblemente, es un terreno en el que el Tribunal Constitucional y el Tribunal Supremo deben ejercer un papel central como garantes, cada uno en su ámbito, de los derechos de aquellos que pudieran, al socaire de una mal entendida diversidad cultural, sufrir esa opresión. Una buena forma de racionalizar esta paradoja, como efecto de la globalización y su incidencia en el ocaso de la modernidad y los albores de la posmodernidad, es la mirada hermenéutica que, como paradigma de conocimiento, se convierte en un modelo de comprensión e interpretación. 


\section{VI}

Terminaré estas reflexiones transitando terrenos por los que no debería caminar más de lo necesario, dada mi bien advertida diletancia. La actual filosofía hermenéutica tiene su hito fundacional en 1960 con la obra de corte neoclásico Verdad y método de Hans-Georg Gadamer, en la que se hipotrofia su naturaleza de ciencia, subrayándose, por el contrario, su cualidad artística: una suerte de actitud o talante ante las cosas. Esto resulta acentuadamente advertible en una España que en aquel año no pertenecía a la Europa hermenéutica sino a una oscura tradición antihermenéutica: la España de los Traductores de Toledo y de las tres culturas que padecía una Escolástica asfixiante y alcanforada, con un tufo eclesiástico cuasi-dogmático.

Digo todo esto porque la hermenéutica, tanto en España como fuera, constituye ya una actitud fundamental $-\mathrm{y}$ fundacional- de la filosofía, acaso como su consciencia crítico/críptica, la cual nunca debería convertirse en doctrina cerrada, puesto que su misión es precisamente abrir los textos a su textura y no abandonarlos a su letra positivizada.

Trasladando esta tendencia al ámbito de la Administración de Justicia, la única respuesta para lograr una percepción sociológica favorable de la función hermenéutica encomendada a las altas instancias jurisdiccionales radica en la expectativa cultural de que los jueces deben comportarse independientemente. Ser un juez en los Estados Unidos es, en palabras del Magistrado de su Tribunal Supremo Stephen Breyer «en parte un estado mental, una cuestión de expectativas, hábito y creencias, no sólo entre los jueces, abogados y legisladores, sino entre millones de personas.». En la medida en que la sociedad, merced a medidas de transparencia y acceso a la información, se forma una opinión sobre la actividad de los tribunales, la confianza pública en el Poder judicial se incrementa de manera exponencial. La razón más importante para confiar en que el fallo de un juez será eficaz, más allá de medidas coercitivas o garantías institucionales para su acatamiento, es de índole cultural y no institucional. La ciudadanía 
ha interiorizado el acatamiento natural de los fallos de los tribunales desde la premisa moral de que, si los casos son sustanciados por jueces imparciales, libres de influencia política, los justiciables se conducirán de acuerdo con la ley y con su interpretación judicial.

Estamos por tanto ante lo que se podría denominar un ejercicio de «legitimidad social», es decir, el grado de confianza y de credibilidad social que una institución (el sistema de Justicia en este caso) amerita entre la ciudadanía. Es éste un rasgo imprescindible de los sistemas de Justicia, no un atributo opcional o contigente: de una Justicia eficiente, pero sin autoridad moral difícilmente pueden esperarse frutos. El buen sistema de Justicia debe generar en sus justiciables (reales o potenciales) el convencimiento de que sus asuntos van a ser tratados no sólo diligente y competentemente sino además de la forma más ecuánime, recta y equilibrada posible. De esto último depende fundamentalmente su fiabilidad, es decir, su legitimidad social. Adviértase como, de no ser así, resultaría injustificable la expropiación a los particulares de la tentación de hacer justicia por su cuenta, no en vano, la potestas del Poder judicial es necesaria pero no suficiente para que el sistema se muestre como confiable y digno de respecto; para ello precisa además de auctoritas, es decir, de la capacidad moral para emitir una opinión cualificada sobre una decisión. El nivel de legitimidad social correspondiente a un sistema de Justicia puede ser entendido como el residuo cristalizado de la forma en que la ciudadanía le percibe y evalúa en relación con rasgos básicos tales como su nivel de independencia e imparcialidad y, sobre todo, su grado de accesibilidad para el usuario, el trato que le dispensa y su margen de diafanidad a la hora de dar cuenta de su funcionamiento de conjunto, sin que además, este rasgo institucional objetivo pueda establecerse o imponerse legislativamente.

Mantener y cultivar esa confianza, plantea además un formidable reto para quienes tienen la responsabilidad de proponer y nombrar a los jueces de los escalones más altos de la jurisdicción, pues ello implica que la propuesta y selección se acomode a estándares de excelencia que en 
forma alguna pueden ser rebajados por razones espurias o al socaire de intereses particulares, porque una sociedad cada vez más implicada en la Administración de Justicia no va a consentir que sus empleados en tan importante función no estén a la altura de sus exigencias. La ciudadanía ha adquirido ya plena conciencia de estar viviendo en un régimen de libertades y de estricto sometimiento a la legalidad, por lo que las expectativas respecto al modo de actuar de la Justicia corren parejas a los crecientes niveles de exigencia que se manifiestan en la política, la economía o el consumo. En este sentido, la Justicia debe también rendir cuentas al cuerpo social sobre el desempeño de sus funciones, como cualquier otra una institución pública que se financia presupuestariamente, desempeñando un servicio público y que, por ende, debe quedar sujeta a una evaluación periódica en cuanto a la calidad en el cumplimiento de sus funciones, como cualquier otro organismo público.

Unas expectativas que tienen su rubicón precisamente en coyunturas sociopolíticas como las actuales. Y es que de la misma forma que legislar en este contexto acarrea el riesgo de confundir más que sistematizar y de desorientar más que guiar, producto de premuras y urgencias siempre desaconsejables cuando de hacer leyes se trata; juzgar en tales condiciones exige del juzgador un aún mayor esfuerzo de ecuanimidad y equidad, ponderando elementos no siempre obrantes en el plano positivo. En un periodo tan convulso como el actual, pero radicalmente más violento como fue la Alemania de Weimar, surgió un pensamiento jurídico sostenido en la importancia de la persona, del ser humano como factor ponderante y transformador del Derecho, como alternativa al paradigma schmittiano en el que el Poder judicial no protegía la Constitución, sino que era el Kaiser del Reich su único defensor en un esquema de control concentrado, que al sustanciarse en el proceso de interpretación y aplicación, nos brindaría la oportunidad de objetivar la norma aplicable a través del debate generado durante el pre-juicio del aplicador del Derecho. Esta tesis, además, se cohonestaba de manera admirable con la corriente neoconstitucionalista iniciada precisamente tras 
la II Guerra Mundial en el seno del Bundesverfassungsgericht -Caso Efels BVerfGE 6, 32-, en la que se subrayaba la importancia de la magistratura, como herramienta modeladora y decantadora de la norma aplicable, pasando a ocupar un lugar institucional clave en la defensa del antipositivismo jurídico frente al iuspositivismo de nuevo cuño. Nótese como nuestra justicia virreinal, muy anterior por tanto a Weimar, tampoco se basaba exclusivamente en el Derecho positivo, sino que brotaba, en cada caso concreto, de la figura del juez quien, de manera singularizada, indicaba dónde estaba la justicia. De ahí la nuclear importancia de la figura del oidor indiano, que priorizaba la exégesis judicial, frente al valor normativo de los preceptos generales, ponderando en cada caso el rigor de su decisión, atendiendo especialmente a factores de oportunidad y conveniencia.

En un contexto histórico-social en el que vuelven a confrontarse regla y principio, disposición y valor, precepto y derecho, cuando más grande y grave es la brecha entre administrado y Administración, entre poderdante y apoderado, entre servidor y servido, se impone más que nunca la tarea de transmitir a la sociedad la idea de que la Justicia está a su servicio: tramitar es servir, juzgar es servir, informar es servir, dar fe es servir, proteger es servir, asesorar es servir. Es imprescindible que merced a unas políticas de transparencia y accesibilidad adecuadas a las singularidades de la Administración de Justicia, se conquisten prosélitos que den testimonio de formar parte del engranaje institucional que permite que las previsiones constitucionales y legislativas tengan su reflejo en la vida diaria y real de los ciudadanos. El derecho a la vida y a la integridad física, a la libertad y a la seguridad, a la tutela judicial efectiva o a la igualdad, entre los fundamentales que reconoce nuestra Constitución $\mathrm{y}$ todo el resto del articulado que rige nuestra convivencia requiere en cada caso de un terminal humano que materialice esa previsión normativa: el juez que ampara los derechos del justiciable, el fedatario que certifica la legalidad de la actuación procesal, el fiscal que persigue el delito, el forense que arroja luz sobre la muerte acaecida...esa intermediación 
entre el plano del ser y el deber ser y el objetivo de que ambos espacios guarden la menor distancia posible entre ellos, se convierte en el más importante estímulo para la Administración de Justicia. Y ese objetivo, como ya se ha dicho aquí, no puede venir únicamente de la mano de las previsiones legales, necesarias sin duda, pero absolutamente insuficientes si no se logra alcanzar esa legitimación social, verdadero marbete identificativo de la Justicia de calidad, y únicamente alcanzable desde la independencia, la transparencia, la accesibilidad y la excelencia hermenéutica.

La civilización romana tenía clara la diferencia entre poder y autoridad. La potestas pertenecía al gobernante; la auctoritas, al sabio. El poder proviene de la ley; la autoridad, del conocimiento, siendo impensable que el poder interfiriese en el plano de la sabiduría. Nuestro paisano Quintiliano, el insigne rétor del siglo I a. de C., decía que en la frente del orador Tracalo brillaba la autoridad. Aplicando aquí los mimbres de la filosofía política del recordado romanista Alvaro d'Ors, si la Administración de Justicia lograra ser socialmente reconocida como sabia y ecuánime y no únicamente identificada como poderosa y distante, sus sentencias y resoluciones vendrían ab origine investidas de un grado de respetabilidad inalcanzable si únicamente las refrenda el imperio de la Ley.

Y es que ya lo dijo Valle Inclán en el teatro Fontalba de Madrid una noche de finales de octubre de 1927, durante el estreno de la comedia $E l$ hijo del diablo, del poeta catalán Joaquín Montaner. Antes de que finalizara el segundo acto, don Ramón comenzó a vociferar “iMuy mal, muy mal!" de forma tan desmesurada que hubo de interrumpirse la representación. Los agentes se acercaron a la butaca que ocupaba el excéntrico gallego para llevárselo a comisaría, y se presentaron diciendo:

iSomos la autoridad!

a lo que el dramaturgo replicó:

- Aquí, en el teatro, yo soy la única autoridad, pues soy crítico. 
Naturalmente, los agentes de la potestas se llevaron al detentador de la auctoritas, pues la fuerza se impone momentáneamente a la razón, pero la crítica literaria no tardó en ensalzar la actuación de Valle Inclán, que con sus gritos logró sepultar la mediocre pieza de Montaner. Si queremos que la Justicia sea algo más que papel de oficio testimoniado, hagamos de ella, entre todos, una institución moralmente intachable, reflejo de una hermenéutica integradora, inclusiva y cohonestada al contexto socio cultural en la que se desarrolla.

Raúl C. Cancio Fernández
Tribunal Supremo de España
Pza Villa de París s/n
28071 Madrid (España)
raulcesar.cancio@justicia.es 